\title{
A Rare Case of Ball Valve Effect of Vocal Cord Papillomas in a Child: An Anaesthetic Challenge
}

\author{
Reema Aggarwal $^{1^{*}}$, Gurpreet Singh ${ }^{2}$ \\ ${ }^{1,2}$ MM institute of Medical Sciences and Research Center, Mullana, Ambala

\begin{abstract}
Vocal cord papillomas are rare growths of viral etiology caused by human papillomavirus (HPV). Large polyps are known to obstruct glottic opening and can cause acute airway obstruction. We report a case of 4-year-old male child with progressive hoarseness of voice and stridor posted for excision of vocal cord papillomas. Paediatric age of the patient and the position of the growth obstructing the glottic opening at vocal cords provided an extremely challenging environment for induction of anaesthesia.
\end{abstract}

Keywords: vocal cord papilloma, hoarseness, spontaneous ventilation, anaesthesia

\section{Background}

Vocal cord papillomas are small wart-like growths caused by the Human Papilloma Virus (HPV). ${ }^{1}$ The disease is also known as recurrent respiratory papillomatosis or RRP. These polyps are known to recur and may require repetitive surgery. The patients are often misdiagnosed as asthma and croup. These growths may involve a part or whole of vocal cords. In paediatric patients with an already narrow glottis, the initial symptoms may be mild i.e. weak cry, inability to phonate properly, benign cough and sore throat. These symptoms however progress over short a time to difficulty in breathing, stridor, total loss of voice, difficulty in lying down and acute air hunger. Treatment of papillomas requires surgical removal with laser therapy or with scalpel knife during micro laryngoscopy. We

\footnotetext{
*Correspondence: Reema Aggarwal

E mail: docreema123@gmail.com

https://orcid.org/0000-0003-1082-7901

Received: 05/07/2021

Accepted: 26/09/2021

DOI: https://doi.org/10.4038/slja.v29i2i.8885
}

report a rare case of paediatric vocal cord papilloma causing near complete obstruction of vocal cords. In our case, surgeons performed the surgery with Microdebrider using the micro laryngoscope.

\section{Case report}

A 4-year-old male child weighing $15 \mathrm{~kg}$ presented to the paediatric clinic with hoarseness of voice for 2 months, which had worsened gradually over the last one month to aphonia and continuous cough. Progressive difficulty with noisy breathing was noted by the parents in the preceding week with low grade fever over the last 3 to 4 days. Child was initially managed with antibiotics and nebulization considering it to be a laryngitis or upper respiratory infection. However, in the absence of response to treatment given, the ENT opinion was sought. Indirect laryngoscopy was performed by an otorhinologist and noted multiple papillomas on both vocal cords obstructing the laryngeal inlet. The surgical team could not completely visualize and comment on the extent of involvement of glottis. However, they could convey that the posterior part of the cords appeared free from growth and a smaller size tube could possibly be 
accommodated. Physical examination revealed pulse rate of $120 / \mathrm{min}$, respiratory rate of $30 / \mathrm{min}$, irregular and noisy breathing with chest retractions suggestive of labored breathing. Saturation on room air was $95 \%$. All routine lab investigations were within normal limits. Echocardiography was done and was reported normal. Procedure was explained to parents and informed consent was taken. Considering the potential loss of patent airway during induction of anaesthesia, consent for emergency tracheostomy was also obtained from the parents. It was decided to secure airway with graded sevoflurane inhalation while maintaining patient on spontaneous respiration. Preoperative sedative medications were not given. Smaller size endotracheal tubes, tracheostomy tube, and resuscitation cart were checked and kept ready. Pre-induction, all standard monitors were attached, baseline parameters recorded and noted.

Intravenous atropine $10 \mu \mathrm{g} / \mathrm{kg}$ was given. Patient was induced with $100 \%$ oxygen and sevoflurane, concentration progressively increased from 2$6 \%$. On achieving deeper plane of anaesthesia, patient was noted to have increased chest retractions possibly due to ball valve phenomenon. No breath sounds heard on auscultation of chest with loss of end tidal $\mathrm{CO}_{2}$ tracing $\left(\mathrm{ETCO}_{2}\right)$ suggestive of total obstruction of airway. Intubation was attempted using CMAC video laryngoscope D-Blade no 2. A mass could be visualized obstructing the airway almost completely. However, a tiny gap was visible in the posterior part of the vocal cords, size 4 ID, uncuffed endotracheal tube was negotiated across and ventilation confirmed by auscultation and return of $\mathrm{ETCO}_{2}$ tracing (Figure 1). Anaesthesia was maintained on oxygen, nitrous oxide, sevoflurane and intravenous atracurium and

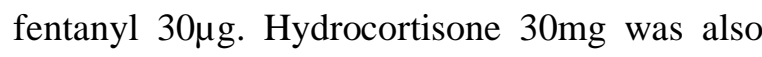
given intravenously.

After the excision of papillomas, the anterior commissure and the anterior part of vocal cords

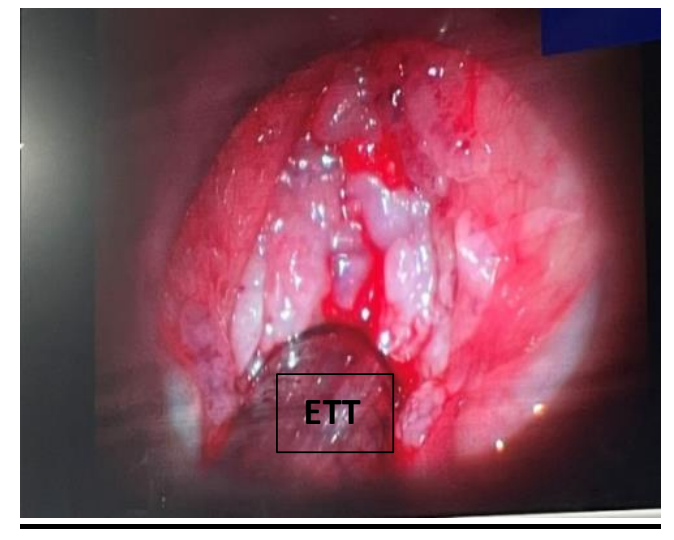

Figure 1. Laryngeal view, immediately after intubation showing multiple vocal cord papillomas obstructing the laryngeal inlet; vocal cords, not clearly visible. ETT: Endotrachel tube

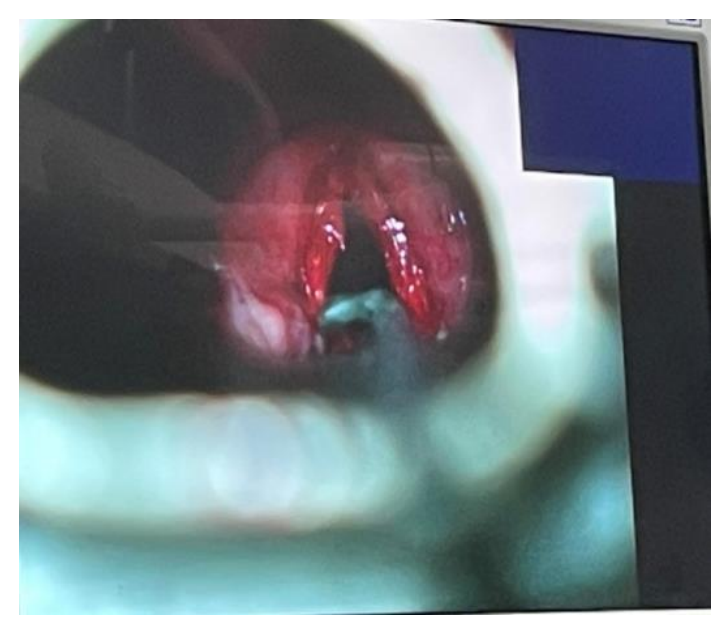

Figure 2. laryngeal view, after excision of vocal cord papillomas showing wider opening between the vocal cords.

could be visualized, and an adequate glottis clearance was achieved (Figure 2).

Following the excision of papillomas, significant air leak was present around the ETT and therefore we changed the tube to a larger size intraoperatively. Thorough suctioning of oral cavity and ETT was done, reversed and extubated awake in the lateral position to avoid aspiration. The child was shifted to post anaesthesia care unit for monitoring. Postoperatively, saturation was maintained around $98 \%$ on room air with no 
respiratory distress and the child was discharged on 6th postoperative day.

\section{Discussion}

Papillomas can develop anywhere along the respiratory tract, but most common sites are larynx and vocal cords. ${ }^{3}$ Less often it can affect oral cavity, trachea and bronchi. Most common presentation of vocal cord papillomas is hoarseness of voice, which can progress to lifethreatening airway obstruction. Some patients may develop dysphonia or aphonia. Paediatric patients may have a weak cry, episodes of choking and failure to gain weight. Additionally, they can have chronic cough, dysphagia and sensation of foreign body in the throat. Papillomas may recur after removal and then called as recurrent respiratory Papillomatosis (RRP). ${ }^{4,5}$ The disease is categorized into two, juvenile-onset form and adult-onset form. Treatment is removal of papillomas either by surgical excision using micro laryngoscope or with the help of $\mathrm{CO}_{2}$ laser or pulsed dye lasers. However, there is no definite cure as recurrence is common. ${ }^{5,6}$ Preoperatively the child should be evaluated for the degree of obstruction. Indirect or flexible laryngoscopic examination should be done by an experienced otorhinologist and, the site of papillomas and the degree of obstruction should be noted. Heart rate, respiratory rate and oxygen saturation should be assessed preoperatively. An echocardiogram should be done preoperatively as these patients can have pulmonary hypertension. ${ }^{2}$ Airway management becomes challenging in paediatric patients as airway is shared by both surgeons and anesthesiologists. All the resuscitation equipment and difficult airway cart must be kept ready before taking the patient to operation table. ${ }^{1}$ Endotracheal intubation should be attempted, and tracheostomy should be used only as a last resort as the procedure may lead to spread of the disease further into the respiratory tract. ${ }^{3} \mathrm{We}$ planned intubation while maintaining the spontaneous ventilation with inhalational technique and avoided the use of muscle relaxants. Sedatives were avoided preoperatively considering the potential for loss of airway. The muscle relaxants were avoided until intubation was confirmed as loss of muscle tone could have caused ball valve phenomenon leading to total obstruction. ${ }^{3}$ Atropine was given before induction to decrease the secretions. Smaller size tubes should be used as the airway is narrowed, and to improve the surgical access. In our case, there was loss of airway after the induction of anaesthesia and immediate intubation was done to secure the airway and restore ventilation. ${ }^{7}$ Airway can be compromised after the induction requiring immediate intubation or emergency surgical airway. ${ }^{8}$ Apnoeic ventilation and jet ventilation are alternate strategies, but carry risks of hypoxia, hypercarbia and barotrauma making intubation as the safest option. ${ }^{9}$ Advantages of intubation include better control over airway and ventilation with protection from aspiration. Disadvantages are inadequate surgical access and risk of spread of disease. In rare occasions, papilloma can occlude the lumen of ETT making ventilation difficult. Smaller size tubes are helpful but hampers the ventilation and concentration of volatile agents delivered. We preferred intubation over other methods as there was difficulty in mask ventilation due to complete obstruction of airway possibly due to prolapsed papillomas.

\section{Conclusions}

Management of vocal cord papilloma is challenging in the paediatric population and anaesthesiologist should be aware of the potential to obstruct the already narrowed paediatric airway following induction of anaesthesia. Avoiding sedative premedication, maintaining spontaneous ventilation, strict monitoring, vigilance and timely decision making are essential prerequisites for managing airway and ventilation safely in the perioperative period.

\section{References}

1. Andrus JG, Shapshay SM. Contemporary management of laryngeal papilloma in adults and children. Otolaryngol Clin North Am. 2006; 39:135-58. 
2. Bo L, Wang B, Shu SY. Anesthesia management in pediatric patients with laryngeal papillomatosis undergoing suspension laryngoscope surgery and a review of the literature. Int $J$ Pediatric Otorhinolaryngology. 2011; 75:1442-5.

3. Harsh ad PL, Pujari V, Channappa NM Anandaswamy TC. Anesthesia management in a child with laryngeal papilloma causing near complete airway obstruction. Saudi J Anaesth 2015; 9:86- 8 .

4. Li SQ, Chen JL, Fu HB, Xu J, Chen LH. Airway management in pediatric patients undergoing suspension laryngoscope surgery for severe laryngeal obstruction caused by papillomatosis. Pediatric Anaesth 2010; 20:1084-91.

5. Pasquale K, Wiatrak B, Woolley A, Lewis L. Microdebrider versus $\mathrm{CO} 2$ laser removal of recurrent respiratory papillomatosis: a prospective analysis. Laryngoscope 2003; 113: 139-143.

6. Ubale P, Mhamane R, Raju S, Pallavi G, Sharma P. Anaesthetic Management of a child with Laryngeal Papilloma's. Enliven: $J$ Anesthesiology Crit Care Med 2(7):019.

7. Cohen SR, Geller KA, Seltzer S, Thompson JW. Papilloma of the larynx and tracheobronchial tree in children. A retrospective study. Ann Otol Rhinol Laryngol 1980; 89:497-503.

8. Theroux MC, Grodecki V, Reilly JS, Kettrick RG. Juvenile laryngeal papillomatosis: Scary anaesthetic! Pediatric Anaesth. 1998; 8:35761.

9. Miyawaki J, Shono S, Katori K, Sakuragi T, Higa K. Subglottic jet ventilation for pediatric microlaryngosurgery: A case report. $J$ Clin Anesth. 2003; 15:363-5. 